\title{
When Training Is Not Enough: An Appeal to the Work Environment for Transfer of Training in the Bahamian Police Force.
}

\author{
Yvonne Hunter-Johnson \\ The College of The Bahamas ${ }^{1}$
}

\begin{abstract}
This study focused on law enforcement officers' perception of factors within a Bahamian law enforcement agency that impede transfer of training. The study design was qualitative. Fifteen participants took part in the study. Data were collected using two focus groups consisting of managers (Sergeants) and subordinates (Corporals and Constables). The analysis used open coding. The overall results of the study revealed that the officers do not perceive the organization as supporting transfer of training. Recommendations were made to promote a supportive work environment. The findings and practical applications are discussed.
\end{abstract}

\section{INTRODUCTION}

Training and development is an integral component to the growth and development of any organization, whether private or public (Hunter-Johnson, 2012). However, oftentimes, organizations do not factor transfer of training as a part of the learning or training process. Despite this exclusion or oversight, transfer of training is indeed a continuation of the learning process. Transfer of training as affirmed by Baldwin and Ford (1988) "is the degree to which trainees effectively apply the knowledge, skills and attitudes gained in the training context to the job" (p. 63). The concept of transfer of training is crucial in any interdisciplinary academic, technical or professional setting. Within these distinctive settings, a great amount of time and money is invested in training (Cascio, 2000; Noe, Hollenbeck, Gerhart, \& Wright, 2006; Velada, Caetano, Michel, \& Kavanagh, 2007). Dolezalek (2004) asserts that according to Training Magazine's ongoing industry report, companies in the United States spend more than $\$ 50$ billion annually on formal training. Additionally, the average employer in the United States spent an average of $2.2 \%$ of payroll dollars in 2002 on education and training (Sugrue, 2003) and in Europe $3.2 \%$ of annual salary (Morrow, 2001). Similarly, within law enforcement in the Bahamas, a considerable amount of money is invested in training and training initiatives by the governments of the Bahamas and the United States.

\footnotetext{
${ }^{1}$ Yvonne Hunter-Johnson, School of Education, The College of The Bahamas, P.O. Box N-4912, Nassau, Bahamas. Acknowledgments: The author is grateful to members of the Royal Bahamas Police Force who participated in this study.

E-mail: yjohnson@cob.edu.bs

APA reference: Hunter-Johnson, Y. (2013). When training is not enough: An appeal to the work environment for transfer of training in the Bahamian police force. The International Journal of Bahamian Studies, 19, 3-14. https:// doi.org/10.15362/ijbs.v19i1.184
}

(c) Y. Hunter-Johnson, 2013. Journal compilation (C)The International Journal of Bahamian Studies, 2013 
Like financial commitment, time also plays a crucial role as it relates to investment in training and transfer of training. With the progression of research related to transfer of training, there has been a constant discussion regarding the lapse in time to apply what was learned and the amount of knowledge diminishing over that time period. Initially, Baldwin and Ford (1988) contended that $10 \%$ of knowledge learned while in the training environment is actually applied to the work environment. However, there are other researchers who suggest that 10 to 15 $\%$ of knowledge is actually applied to the work environment (Broad \& Newstrom, 1992; Burke \& Baldwin, 1999; Facteau, Dobbins, Russell, Ladd \& Kudisch, 1995). Saks (2002) later revealed that $40 \%$ of trainees fail to transfer immediately after training, $70 \%$ falter in transfer one year after the training program and only 50\% of training investment results in organizational or individual improvement. Other researchers and practitioners concur that knowledge is diminished due to the time lapse in the application of knowledge to the work environment (Wexley \& Latham, 2002; Velada et al., 2007).

Despite the investment of time and money, training is fruitless if the knowledge learned in the training environment is not applied to the work environment. Further, despite such investment in training, there is no assurance or initial evidence that there will be a return on the investment. On this note, it is imperative that organizations provide sufficient evidence that the training efforts are being fully utilized (Cascio, 2000; Dowling \& Welch, 2005, Hunter-Johnson \& Closson, 2011; Velada et al., 2007). In other words, organizations should ensure that the work environment is supportive, conducive and appealing to ensure that knowledge learned in the training environment can be applied to the work environment.
Law enforcement, unlike many other organizations, is considered to be an essential service which requires its employees to be on the cutting edge and equipped with the ability to implement best practices. On this premise, transfer of training is crucial in law enforcement and the work environment should facilitate, not inhibit such transfer.

This paper seeks to address two questions: First, what are officers' perceptions of support within the work environment from managers, supervisors, and peers for implementing transfer of training? And second, what are officers' perceptions of factors that prevent the work environment from being supportive to transfer of training? The theoretical framework that acts as the lens to illuminate the transfer of training process in this study is the Baldwin and Ford (1988) Transfer of Training Process. Although an earlier model, it acts as a foundational platform to other transfer of training models (Holton, 1996; Kontoghiorghes, 2002; Thayer \& Teachout, 1995). This foundational model of transfer of training focuses on three specific categories: (a) individual characteristics, (b) training design, and (c) a supportive work environment. Within the work environment component, unlike other transfer of training models, such as Kontoghiorghes (2002), Holton (1996), or Thayer and Teachout (1995), Lave and Wenger (1991) uses the communities of practice model. This model focusses on learning in practice as a matter of acculturation, of joining a community of practice, rather than on the application of skills or principles which operate independently of the social context. It incorporates support from supervisors and peers coupled with the opportunity to perform learned behaviours on the job (Baldwin \& Ford, 1988). On this premise, this theoretical framework was selected. 


\section{Literature Review}

There has been an increase in the literature related to transfer of training and factors that influence or impede transfer of training. However, there are few studies that focus on the work environment and, in particular, support from supervisors, managers and peers as factors that influence transfer of training. Additionally, there was no literature that focused on transfer of training and law enforcement from a Caribbean perspective.

Lim and Johnson (2002) examined factors that influence transfer of training in a Korean three-week human resource training program. The results from this study revealed that the following factors influenced transfer of training: lack of opportunity to apply on the job $(64.3 \%)$; not directly related to my job (15.0\%); lack of understanding $(9.3 \%)$; planning for future use $(6.9 \%)$; difficult to apply due to organizational problems $(2.9 \%)$; not applicable to Korean situation (1.0\%); and lack of equipment to use $(0.7 \%)$. Work environmental factors that influence transfer of training were organizational commitment for training, goals of the department match with new learning, climate of supportive and open communication, employees have been valued, reward or incentive for attending training, organizational hierarchy, and change-resistant climate.

At the individual level, work environment factors that influenced transfer were discussion with supervisor to use new learning, supervisor's involvement or familiarization with the training, positive feedback from supervisor, opportunity to use new learning, positive feedback from coworkers, availability of tools, equipment, or materials, pace of work flow, lack of mentor or role model, negative feedback from supervisor, lack of pace of work flow, availability of mentor role model, lack of tools, equipment, or materials, negative feedback from co-workers and lack of opportunity to use new learning.

Cromwell and Kolb (2004) studied the relationship between four work-environment factors (organization support, supervisor support, peer support, and participation) in a peer support network. The results revealed that all four work environment factors have a statistically significant positive correlation with transfer.

Velada et al. (2007) conducted a quantitative study of 182 participants employed by nine grocery markets in Portugal. The objective of the study was to examine the relationship between three types of predictors on transfer of training: (a) training design, (b) individual characteristics, and (c) the work environment. The results from the study revealed that transfer design, performance self-efficacy, retention of content, and work environment (feedback) all were significantly related to transfer of training. However, supervisor support did not significantly influence transfer of training.

\section{Training and Law Enforcement}

Within law enforcement, there are basically two categories of training: pre-service or recruit training and post-appointment training or professional development. However, there has been an evolution in law enforcement training due to societal, technological, political, and economic demands coupled with the introduction of Community Oriented Policing (McCoy, 2006). Law enforcement training has evolved from traditional military or police practices (Birzer \& Tannehill, 2001) to place emphasis on technical and procedural skills taught in a more learner-centered environment with greater focus on developing problem-solving skills. This evolution in training now produces law enforcement officers who are equipped with 
effective communication skills, problemsolving skills, decision-making skills, and good basic human relations skills.

Within the Bahamian police force, there has also been an evolution in law enforcement training. Training, which was initially hosted at the police headquarters and had the single objective of recruit training based on traditional military practices, has now evolved to include a myriad of professional development training and certifications (Freeman Johnson, personal communication, April 2013). Training and development has also emerged as one of the top ten priorities within the organization. According to the Royal Bahamas Police Force Commissioner's Policing Plan (2013), training and development of officers is the organization's sixth priority with emphasis on professionalizing the service. It is hoped that such emphasis on training and development will promote positive interaction between the public and the police, restore the image of the organization and strengthen the confidence and trust of the public in law enforcement officers. In an effort to host this escalation of training, the Police Training College was constructed in 1973. Training in the 21st century in this law enforcement agency is not merely to satisfy local demands but to meet global demands and expectations in law enforcement.

At the Bahamian Police Training College, there are four departments (or schools) that provide professional development training. These schools are: (a) Detective Training School, which provides training courses such as intelligence training, drug investigations, sexual offences investigations, initial, intermediate, and advanced investigation training, initial, intermediate, and advanced scenes of crime investigation training, fingerprinting, initial steps at the crime scene and photography; (b) In-Service School, which offers developmental and refresher courses for Constables, Corporals, and Sergeants; (c) Specialist Training School, which facilitates technical training such as driving, firearms, and defensive tactics; and (d) Computer Training. Within the respective departments, each training program is offered at least twice a year. Training courses range from one week to five weeks and accommodate between 10 to 30 participants per course. The objective of professional training is to provide participants with the necessary skills, knowledge, and values required to perform competently at their level within their respective work environment.

\section{METHODS}

The research design utilized for this study was a qualitative approach. The target population for this study was officers within a Bahamian law enforcement agency. These officers, approximately 2,500 in total, are responsible for the maintenance of law and order, prevention and detection of crime, and maintenance of peace within the country. To ensure that these officers are equipped with the knowledge, skills, and abilities to perform their duties effectively, officers attend training locally and internationally. Officers are strongly encouraged to take professional development training for many reasons such as the need to be trained, the need to be promoted, and the need for new knowledge, skills and abilities. The Bahamian police department is organized in a hierarchical structure consisting of nine ranks, which is used by the force at all stations, departments, and family islands districts in more than 100 locations throughout the islands (HunterJohnson, 2012).

To ensure population validity, a sample was randomly selected from lower-ranking officers (Constables, Corporals and 
Sergeants) who attended professional development training within the last year at the training academy, included both genders, between the ages 18 and 60 years, and who were full-time active employees within the police department. Approximately 500 officers receive varied training at the lower ranks within the organization. All focus group members met the inclusion criteria and their participation was voluntary.

There were two focus groups conducted: (a) subordinate officers: Constables and Corporals, and (b) managers: Sergeants. Demographics for the two focus groups are presented in Table 1. Of the 15 law enforcement officers interviewed, six (40\%) were females and nine $(60 \%)$ were males. The hierarchical rank structure ranged from Constable to Sergeant of whom six $(40 \%)$ were Sergeants, seven (46\%) were Corporals, and two (13\%) were Constables. The academic levels of the law enforcement officers varied and included law enforcement officers with a high school diploma, five (33\%); Associate Degree, two (13\%); Bachelor Degree, four (27\%); Master's Degree, one (7\%); and Other, 3 (20\%).

The data received from the focus group were prepared, organized and transcribed. Upon completion of the transcription process, the data were analyzed into themes through a process of open-coding (Strauss \& Corbin, 2007). Open coding is defined as the process of " "naming and categorizing' of a phenomenon through close examination of data" (Strauss \& Corbin, 2007, p. 62). A phrase/theme was categorized as the unit of analysis. The data were represented in figures, tables, and/or discussions for interpretation. To ensure validity and reliability of the data, they were checked by a second researcher (peer reviewer) who verified the coding system used and the results.
Table 1

Demographic Characteristics of Focus Group Participants

\begin{tabular}{|c|c|c|c|c|}
\hline Variable & $\begin{array}{l}\text { Constables \& } \\
\text { Corporals } n=9\end{array}$ & $\%$ & $\begin{array}{c}\text { Sergeants } \\
n=6\end{array}$ & $\%$ \\
\hline \multicolumn{5}{|l|}{ Gender } \\
\hline Male & 7 & 77.8 & 2 & 33.3 \\
\hline Female & 2 & 22.2 & 4 & 66.7 \\
\hline \multicolumn{5}{|l|}{ Age } \\
\hline $21-30$ years & 2 & 22.2 & 3 & \\
\hline $31-40$ years & 5 & 55.6 & 3 & 3 \\
\hline $41-50$ years & 2 & 22.2 & & 3 \\
\hline \multicolumn{5}{|l|}{ Current Rank } \\
\hline Constable & 2 & 22.2 & & \\
\hline Corporal & 7 & 77.8 & & \\
\hline Sergeant & & & 6 & 100 \\
\hline \multicolumn{5}{|c|}{ Highest Educational level } \\
\hline High School & 4 & 44.4 & 1 & 16.67 \\
\hline Associate & 1 & 11.1 & 1 & 16.67 \\
\hline Bachelor & 4 & 44.4 & 1 & 16.67 \\
\hline Other & & & 3 & 50 \\
\hline \multicolumn{5}{|c|}{ Current Posting } \\
\hline Patrol Officer & 2 & 22.2 & 1 & 16.67 \\
\hline Station Duties & 4 & 44.4 & 1 & 16.67 \\
\hline Detective & 3 & 33.3 & 2 & 33.33 \\
\hline Family Island & 3 & 33.3 & 1 & 16.67 \\
\hline Administration & 3 & 33.3 & 1 & 16.67 \\
\hline \multicolumn{5}{|c|}{ Years of Service } \\
\hline$<5$ years & 2 & 22.2 & & \\
\hline 6 to 10 years & 1 & 11.1 & & \\
\hline 11 to 15 years & 2 & 22.2 & 1 & 16.67 \\
\hline 16 to 20 years & 2 & 22.2 & 3 & 50 \\
\hline 21 to 25 years & 2 & 22.2 & 1 & 16.67 \\
\hline$>26$ years & & & 1 & 16.67 \\
\hline
\end{tabular}

\section{RESULTS}

\section{Constables' and Corporals' Focus Group}

The major themes that emerged from the first focus group (Constables and Corporals) relating to officers' perception of support within the workplace from manager, supervisors, and peers for implementing transfer of training were (a) favouritism/cliques, (b) resistance to change, and (c) attitude towards training. The participants were specifically asked what were their perceptions related to support from managers, supervisors, and peers 
related to transfer of training in the work place. Below are examples of statements made by the officers.

One participant responded that the level of support an officer received from managers, supervisors, and peers is dependent upon the individual officer. The participant elaborated by saying:

Sometimes I feel as though it is the supervisor and if you are not in the clique, you would not receive the relevant training to be able to apply it to the work environment. It causes me to wonder if this is based on personality, gender, or personal relationships within the organization determining who would get training to be able to apply to the work environment.

The negative attitude of managers, supervisors, and peers towards training was an emerging theme. For example, one participant responded by stating:

Some officers have a negative attitude towards training. This is a major barrier to training and the ability to apply what is learned in the training environment to the work environment. This makes it very difficult for people to apply the knowledge learned to the work environment.

The final theme that emerged related to support from managers, supervisors, and peers, was resistance to change. One participant responded:

I have found that those senior officers are not open to change as it relates to those officers that attended training and returned to the work environment. The older senior officers, especially, are not open to new ideas and new knowledge and are not willing to change. There are some instances where the younger officers who would have been exposed to training would often be more receptive to training and the ability to apply the knowledge learned from training to the work environment.

\section{Sergeants' Focus Group}

Within the Sergeants' focus group, the participants were asked what level of support they perceived they received within the workplace from their manager, supervisor, or peers as it related to applying new knowledge that was learned in the training environment to the work environment. As a result of this question and discussions among the group, it appeared as though the participants did not perceive themselves as receiving support from managers, supervisors, and peers. The major themes that emerged from the focus group were (a) limited training of peers and supervisors, (b) attitude and individual personality, and (c) lack of value of knowledge.

As it relates to limited training of peers and supervisors one participant indicated:

The practical knowledge that was learned on the training course, when I try to reinforce that with the officers, they would not take it serious despite the seriousness of the training. I think they did this because of their limited individual level of training and their maturity level. I think that if officers do not receive that particular training directly, they are not interested in the knowledge from the training. You would attend a training course, return to the work environment, and try and train. However, the officers do not take it seriously.

As it relates to attitude and individual personality as an influence on level of support, one participant indicated:

I know that people say personality does not have anything to do with it but 
personality still plays a big role in getting things done. The manner in which you deal with people whether on the job or off the job would be a factor in the amount of support you would receive in the work environment. Sometimes you have to get in the inner spirit of someone before you can get that level of support from that individual. The knowledge you have to transfer is more likely to be receive because of your personality and whether or not you are liked or disliked by peers/supervisor and managers.

The final theme that emerged related to perception of support by managers, supervisors, and peers was lack of value of knowledge:

I think that supervisors/managers and peers need to have an appreciation of the knowledge that you have in order to receive their support and the information to be transferred to the work environment. For example, in scenes of crime in 2004 when there was support from supervisor, there was no problem obtaining the materials needed to transfer the knowledge learned in training to the work environment. However, when there was a switch in the supervisor to one that did not have an appreciation for scenes of crime, there was great difficulty with obtaining the materials needed to apply what was learned in the training environment back to the work environment.

When asked what officers perceived were other factors within the work environment that impede transfer of training, the following major themes emerged among both focus groups: (a) theory versus practice in promoting learning, (b) personality, and (c) work environment. Secondary themes that emerged were: (d) lack of interest in new knowledge, (e) traditional versus modern policing practices, (f) mandatory sharing of knowledge, (g) training incentives and access to training, and (h) rank versus knowledge.

Theory versus practice. Within law enforcement, there are usually numerous organizational policies and procedures that influence internal and external training. However, in some instances, the organizational policies on training are not in alignment with what is actually practiced. It is the officers' belief that theoretically, the organization encourages learning and transfer of training. However, practically in the work environment, it is not a reality because of so many workplace barriers. Therefore, theory must be aligned with what is practically being taught and subsequently practiced within the work environment. On this premise, this warrants administration to be "... open minded, thinking outside the box and ensuring systems are in place”.

Personality. Both focus groups identified personality as a factor that impedes support for transfer of training in the work environment. However, the Constables and Corporals focus group identified the personality of the commanding officer as a positive influence. It is the officers' belief that once the commanding officer supports the training initiative, he or she would ensure that the knowledge learned would be applied to the work environment. Subsequently, officers in both focus groups believe that if an officer is not in the clique because of individual personality or is disliked, he or she may not be given the opportunity to be trained and hence will not be able to transfer training. Or, if given the opportunity to be trained, that person may not be granted the same opportunity as someone who is well liked, to share the information learned in the training environment with those in the work 
environment.

Work environment. The culture within the work environment was identified as an impediment to transfer of training by both focus groups. Concerns were expressed regarding inconsistencies between what is being taught at the training college and what is actually enforced by supervisors within the work environment because of the unique cultures within the respective departments. Officers perceive that "the station culture is superseding force policy and what is being taught at the training school".

The Sergeants' focus group also identified work environment as an impediment and believes that even if an officer is motivated to learn and transfer training, if the work environment is not supportive of learning: "I may not be motivated to apply the knowledge learned because I know the negative work environment I came from, I am not motivated to try implementing it because they would not entertain me".

Lack of interest in new knowledge. Within the Constables and Corporals focus group, officers indicated that if officers do not perceive the new knowledge as something that would directly impact them, then in most instances, they would not receive the information. This makes it extremely difficult to apply the knowledge.

Traditional versus modern policing practices. Within law enforcement agencies that are characterized by the old Colonial style, officers expect to do whatever they are told to do without questioning. Modern times have resulted in some changes in policing. On this premise, officers believe "...there should be changes from Colonial policing practices to modern police practices. This would assist in transfer of training". Further, within the Constables and Corporals focus group, it was discussed that there evidently is a clash between "old school policing and modern policing practices as it relates to training and transfer of training". This clash is said to be influenced by the commanding officers. If commanding officers are considered to be young or modern, then training and transfer of training is more visible. However, the more traditional commanding officers often view training “... as an individual gain and not an organizational gain and would not provide the opportunity to share".

Within the Sergeant's focus group, the following secondary themes emerged: (a) mandatory sharing of knowledge, (b) training incentive, (c) limited access to training, and (d) rank versus knowledge.

Mandatory sharing of knowledge. Within law enforcement, communication is essential at all levels to ensure proper networking among inter-related departments, the judicial system and society. However, the participants of the focus group identified communication, particularly how communication is disseminated, as a factor that influenced the transfer of training process. When asked exactly how this impacted the transfer of training process, it was stated that the organization does not mandate nor are there any organizational policies that dictate that the knowledge learned in a training environment (nationally or internationally) be transferred to the work environment.

Training incentive and access to training. The officers believe that the organization does not provide any incentives for officers to transfer knowledge learned to the work environment. Further, not enough officers are provided with international training. This sometimes creates a problem when officers who are exposed try to share their knowledge; there is resistance to the information because of differences in 
knowledge level and appreciation for the knowledge.

Rank versus knowledge. Law enforcement, like other military and semi-military bodies, has a hierarchical rank structure. Within the Bahamian police force, there are currently nine ranks within the rank structure. This often imposes a challenge if the lower ranking officers are equipped with superior knowledge and skills. As one participant stated:

It is very difficult for that information to be disseminated because in our culture, rank is perceived as knowledge or understanding or wisdom or it basically determines who is heard. Sometimes, because someone of a lower rank has that information, it becomes difficult for people to respect that information and disseminate it. So if a Constable goes off on a specific training, and wants to return [to the work environment] he starts with a challenge.

\section{DISCUSSION}

The findings of this study reveal that Bahamian law enforcement officers (subordinates and management) do not perceive support within the work environment from managers, supervisors, and peers for implementing transfer of training. Factors that influenced this perception were favouritism or cliques, attitudes and individual personality, attitude towards training by other officers (lack of value towards training) and resistance to change. All of these factors identified are directly related to behaviours exhibited by supervisors, peers or managers and can be modified with the implementation of proper communication channels and relevant training.

It is suggested that within this organization, in an attempt to garner support from supervisors, peers and managers within the work environment, there should be training introduced at all levels. It should be specifically geared towards behaviour modification, team building, learning communities, organizational change and understanding the relationship between training and transfer of training in essential service. This would attempt to illuminate the significance of training and the consequences of not transferring knowledge to the work environment due to lack of support within the work environment. Additionally, it would attempt to modify behaviours at all level that are impeding the transfer of training process. It is important that all officers, regardless of their rank, understand that the work environment has a significant impact on transfer outcomes. Additionally, the effectiveness of a training program is largely dependent on the trainees' ability to use their newly acquired competencies on the job (Salas, Wilson, Priest, \& Guthrie, 2006).

Further, the findings from this study were consistent with the literature related to work environment in terms of the factors that influence transfer of training: hierarchal structure, work environment culture, training incentives, resources, value of training and opportunity to use the new knowledge (Lim \& Johnson, 2002; Cromwell \& Kolb, 2004). However, it is worth noting that there were additional factors identified as impeding the transfer of training process within this study such as traditional versus modern policing practices, paper versus practice and mandatory sharing of information that were not identified in previous studies on this topic.

Traditional versus modern policing practice was identified as an impeding factor. As law enforcement evolves holistically within this Bahamian law enforcement agency, it is imperative that officers at all levels keep up with the evolution of the force. Training 
requirements, techniques and practices that may have once been considered applicable have changed due to societal, economic, technological and political demands. On this premise, it is imperative that officers (higher ranking officers) are open to embracing change for the betterment of the organization related to training and development. Further, younger officers, who have been exposed to more modern training, need opportunities to apply new competencies in order for them to transfer these to the job (Burke \& Hutchins, 2007).

Additionally, this Bahamian law enforcement agency can provide further opportunities for embracing and transferring modern policing practices learned by designating time and resources for the application of new skills. Supervisors, for example, can modify recent trainees' workloads to increase their opportunities to practice what they learned in the workplace. Or supervisors can allow trainees to verbally share new knowledge in an informal manner within their specific workplace.

The sharing of new knowledge whether formally or informally would address the concern of mandatory sharing of knowledge learned in any training environment to the work environment. It should be stipulated in the organizational policies and/or procedures that officers attending training whether locally or internationally are required to share the knowledge learned in that training environment with the work environment. This mandatory sharing of information could be documented in a learning contract prior to the officer's receiving training.

Paper versus practice was also identified as an impediment to the transfer of training. Officers indicated that policies and practices that are documented as organizational policies and procedures regarding training and development are not being adhered to.
On this premise, it is imperative that the organization implement a proper quality control unit to ensure that organizational policies and procedures are being adhered to regarding training and the implementation of training initiatives.

A limitation to this study was that the study sample consisted of only 15 participants. It is recommended that additional research be undertaken to incorporate the opinions of more officers with a view to diagnosing additional factors within the work environment that influence the transfer of training process. This process can be enhanced by conducting a transfer of training needs analysis in order to first determine the kinds of transfer obstacles that exist in the organizational context for a particular training program (Hesketh, 1997) or the incorporation of the Learning System Transfer Inventory (Holton, Bates, Seyler \& Carvalho, 1997).

\section{CONCLUSION}

The purpose of this study was to determine law enforcement officers' perception of support within the work environment from managers, supervisors, and peers for implementing transfer of training and to determine what officers perceive as factors within the workplace that impede the transfer of training. This study provided insight as it relates to what can be done within the work environment to encourage support from supervisors, peers and managers. Additionally, it revealed possible impediments to the transfer of training process and what can possibly be done by the organization to eradicate those impediments. Lastly, research shows that organizations should not consider the completion of formal training the end of the learning process (Salas \& Stagl, 2009). However, organizations should be aware that transfer of training is a continuation of the learning process. 


\section{REFERENCES}

Baldwin, T. T., \& Ford, J. K. (1988).

Transfer of training: A review and directions for future research. Personnel Psychology, 41, 63-105. doi:10.1111/j.1744-6570.1988.tb00632.x

Birzer, M., \& Tannehill, R. (2001). A more effective approach for contemporary policing. Police Quarterly, 4(2), 233-252. doi:10.1177/109861101129197815

Broad, M. L., \& Newstrom, J. W. (1992). Transfer of training: Action-packed strategies to ensure high payoff from training investments. Cambridge, England: Perseus.

Burke, L., \& Baldwin, T. (1999). First break all the rules: What the world's greatest managers do differently. New York, NY: Simon \& Schuster.

Burke, L. A., \& Hutchins, H. M., (2007). Training transfer: An integrative literature review. Human Resource Development Review, 6(3), 263-296. doi:10.1177/1534484307303035

Cascio, W. F. (2000). Costing human resources: The financial impact of behavior in organization. Cincinnati, $\mathrm{OH}$ : South-Western.

Cromwell, S. E., \& Kolb, J. A. (2004). An examination of work-environment support factors affecting transfer of supervisory skills training to the workplace. Human Resource Development Quarterly, 15(4), 449-471. doi:10.1002/hrdq.1115

Dolezalek, H. (2004). Training annual industry report. Training Magazine, 42(10). Retrieved from www.trainingmag.com.

Dowling, P. J., \& Welch, D. E. (2005). International human resource management: Managing people in a multinational context. (5th ed.). Mason, $\mathrm{OH}$ : Thompson South-Western.
Facteau, J. D., Dobbins, G. H., Russell, J. E. A., Ladd, R. T \& Kudisch, J. D. (1995). The influence of general perceptions of the training environment on pretraining motivation and perceived training transfer. Journal of Management, 21(1), 1-25. doi:10.1016/0149-2063(95)90031-4

Hesketh, B. (1997). Dilemmas in training for transfer and retention. Applied Psychology, 46(4), 317-386. doi:10.1111/j.1464-0597.1997.tb01234.x

Holton, E. F. (1996). The flawed four-level evaluation model. Human Resource Development Quarterly, 7, 5-21. doi:10.1002/hrdq.3920070103

Holton, E. F., Bates, R., Seyler, D., \& Carvalho, M. (1997) Toward construct validation of a transfer climate instrument. Human Resource Development Quarterly, 8, 95-113. doi:10.1002/hrdq.3920080203

Hunter-Johnson, Y. (2012). Perception of a learning organization and factors within the workplace that influence transfer of training. (Doctoral dissertation). Available from ProQuest Dissertations and Theses database. (UMI No. 3548098)

Hunter-Johnson, Y., \& Closson, R. (2011, November). From the shooting range to the street: Training facilitators' perception on transfer of training. Paper presented at the meeting of American Association for Adult and Continuing Education, Indianapolis, Indiana.

Kontoghiorghes, C. (2002). Predicting motivation to learn and motivation to transfer back to the job in a service organization: A new systemic model for training effectiveness. Performance Improvement Quarterly, 15, 114-129. doi:10.1111/j.1937-8327.2002.tb00259.x 
Lave, J., \& Wenger, E. (1991). Situated learning: Legitimate peripheral participation. New York, NY: Cambridge University Press.

Lim, D. H., \& Johnson, S. D. (2002). Trainee perception of factors that influence learning transfer. International Journal of Training and Development, 6(1), 36-48. doi:10.1111/1468-2419.00148

McCoy, M. (2006). Teaching style and the application of adult learning principles by police instructors. Policing: An International Journal of Police Strategies \& Management, 29(1), 77-91. doi:10.1108/13639510610648494

Morrow, T. (2001). Training and development in the Northern Ireland clothing industry. Journal of European Industrial Training, 25(2), 80-89. doi:10.1108/EUM0000000005439

Noe, R. A., Hollenbeck, J. R., Gerhart, B., \& Wright, P. M. (2006). Human resource management: Gaining a competitive advantage, (6th ed.). Boston, MA: McGraw-Hill Irwin.

Royal Bahamas Police Force. (2013). Commissioner's policing plan, 2013. Retrieved from http://www.royalbahamaspolice.org/about us/cop_plan_2013/foreword.php

Saks, A. M. (2002). So what is a good transfer of training estimate? A reply to Fitzpatrick. The Industrial-Organizational Psychologist, 39(3), 29-30. Retrieved from http://www.siop.org/tip/backissues /TIPJan02/pdf/393_\%20029to030.pdf

Salas, E., \& Stagl, K. C. (2009). Design training systematically and follow the science of training, in E. Locke (ed.), Handbook of principles of organizational behavior: Indispensible knowledge for evidence-based management (2nd ed., pp. 59-84). Chichester, England: John Wiley.
Salas, E., Wilson, K., Priest, H., \& Guthrie, J. (2006), Design, delivery, and evaluation of training systems. In G. Salvendy (Ed.) Handbook of human factors and ergonomics (3rd ed., pp. 472-512). Hoboken, NJ: John Wiley.

Strauss, A.L. \& Corbin, J. (2007). Basics of qualitative research. Techniques and procedures for developing grounded theory. (3rd ed.) Thousand Oaks, CA: Sage.

Sugrue, B. (2003). ASTD 2003 State of the industry report. Alexandria, VA: ASTD.

Thayer, P. W., \& Teachout, M. S. (1995). A climate fit transfer model. Retrieved from http://www.dtic.mil/cgibin/GetTRDoc?AD=ADA317057

Velada, R., Caetano, A., Michel, J. W., \& Kavanagh, M. J. (2007). The effects of training design, individual characteristics and work environment on transfer of training. International Journal of Training and Development, 11(4), 282294.

Wexley, K. N., \& Latham, G. P. (2002). Developing and training human resources in organizations (Vols. 3-4). Englewood Cliffs, NJ: Prentice-Hall. 